\title{
A minimally invasive midface suspension
}

\author{
Jorge I. de la Torre, John Lindsey Jr., Dean Cerio, Luis O. Vasconez \\ Division of Plastic Surgery, University of Alabama at Birmingham and Birmingham V.A. Medical Center Birmingham, Birmingham, AL \\ 35294, USA.
} Correspondence to: Dr. Jorge I. de la Torre, MD, MSHA, UAB Plastic Surgery, 500 22nd Street, South - JWB 103 Birmingham,
Birmingham, AL 35294, USA. E-mail: jdlt@uab.edu

How to cite this article: de la Torre JI, Lindsey Jr. J, Cerio D, Vasconez LO. A minimally invasive midface suspension. Plast Aesthet Res 2020;7:11. http://dx.doi.org/10.20517/2347-9264.2019.54

Received: 8 Nov 2019 First Decision: 13 Jan 2020 Revised: 10 Feb 2020 Accepted: 20 Feb 2020 Published: 13 Mar 2020

Science Editor: John Yousif Copy Editor: Jing-Wen Zhang Production Editor: Tian Zhang

\section{Abstract}

Aim: With the normal aging process, the malar fat pad descends vertically, causing a number of characteristic changes to the face. Various techniques have been used to correct ptosis of the malar fat pad.

Methods: The authors describe a technique that is minimally invasive and can be used to correct malar fat pad ptosis. This technique uses a suspension suture to elevate the malar fat pad to a more youthful position. The technique has been successfully used in 71 patients.

Results: All of the cases were performed in the office setting under local anesthesia. There were no complications, and, by patient self-report and physician exam, results have been lasting and satisfactory.

Conclusion: The minimally invasive midface suspension is a safe and successful approach to midface rejuvenation in properly selected patients.

Keywords: Midface rejuvenation, midface suspension, malar fat pad, facial rejuvenation

\section{INTRODUCTION}

The malar fat pad is a critical component of the midface and its descent impacts several aspects of facial aging. It is a fibro-fatty triangular structure that is just below the dermis and subcutaneous tissue. It is superficial to the superficial muscular aponeurotic system (SMAS) ${ }^{[1]}$. This triangular structure has its apex located at the oral commissure; the lateral border is a line from the apex to the lateral canthus; the medial border is a line from the apex to the medial canthus; and the superior border is a horizontal line that runs along the inferior aspect of the lower eye $\mathrm{e}^{[2]}$.

Cc) (i) The Author(s) 2020. Open Access This article is licensed under a Creative Commons Attribution 4.0 International License (https://creativecommons.org/licenses/by/4.0/), which permits unrestricted use sharing, adaptation, distribution and reproduction in any medium or format, for any purpose, even commercially, as long as you give appropriate credit to the original author(s) and the source, provide a link to the Creative Commons license, and indicate if changes were made.

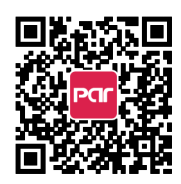




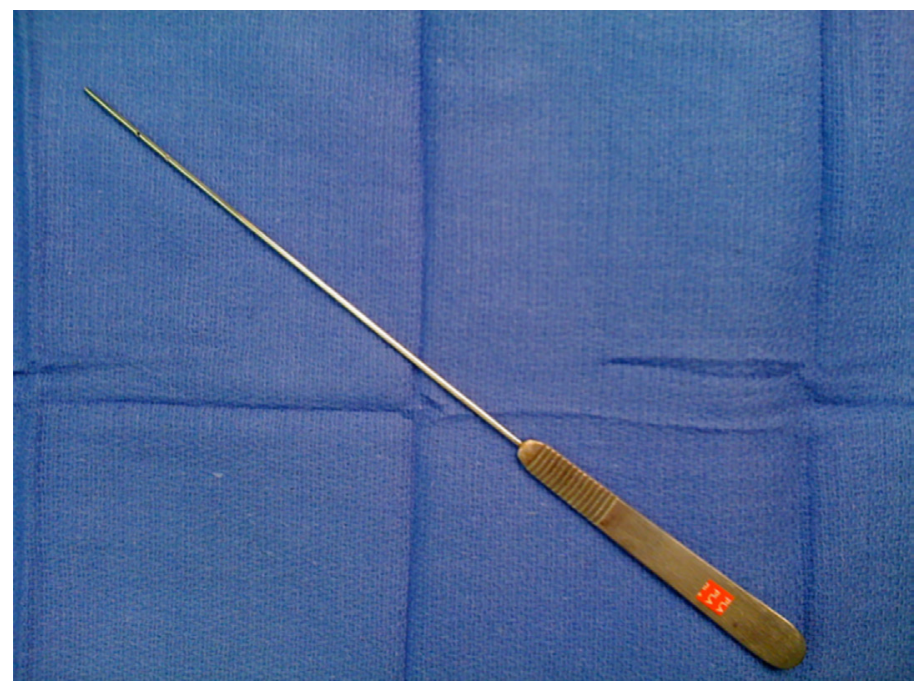

Figure 1. Blunt passing instrument. Note the eye for the suture is $1 \mathrm{~cm}$ from the tip. There is a visible mark $2 \mathrm{~cm}$ away from the tip

Numerous studies have described the etiology of ptosis of the malar fat $\operatorname{pad}^{[1-8]}$. These include gravitational pull, repetitive facial animation, laxity of the retaining ligaments, and loose attachment to the underlying SMAS. The effects of this descent have also been well described, such as hollowing of the infraorbital rim, deepening of the nasolabial folds, and the formation of jowls ${ }^{[1-8]}$. Myriad techniques have been used to rejuvenate the midface, ranging from open surgeries with extensive dissection to closed procedures with barbed sutures and zero dissection ${ }^{[2,3,8-11]}$. Furthermore, there is extensive variability in the location of incisions and the planes of dissection.

Despite the array of treatment options, there is an emerging interest in minimally invasive techniques. Reasons for this development may include shorter operative time, fewer complications, and decreased recovery time ${ }^{[12]}$. Additionally, these types of procedures can generally be performed in the office-based setting with local anesthesia. Patients are also more willing to accept less dramatic results for a less invasive procedure. There are several minimally invasive techniques, such as endoscopic approach with extensive dissection, $\mathrm{U}$-suture suspension with minimal dissection, and unidirectional barbed suture suspension with zero dissection ${ }^{[9,10,13-17]}$. We describe here the Minimally Invasive Midface Suspension (MIMS), which is a technique with a short learning curve, reproducible results, high patient satisfaction, and low risk of complications.

\section{METHODS}

\section{Surgical technique}

The planned incisions are marked with the patient in the upright position. The anchor point incision is marked approximately $1-2 \mathrm{~cm}$ behind the hairline in the temporal region on a vertical line drawn from the superior lateral border of the malar fat pad. The inferior incision is marked along the nasolabial fold along the mid-pupillary line. Both incision sites are infiltrated with 0.5\% lidocaine with 1:200,000 epinephrine. In addition, local anesthesia is administered as a block to the infraorbital and supraorbital nerves. After allowing the epinephrine to take effect, the temporal incision is made with a 15-blade approximately $2 \mathrm{~cm}$ in length beveling with the direction of the hair follicles. Gentle blunt dissection can be performed to dissect down to the level of the deep temporal fascia. A small stab incision is made near the nasolabial fold with an 11-blade. A specially designed long, blunt passing instrument [Figure 1] is then introduced through the naso-labial stab incision and directed through the malar fat pad toward the temporal incision in a subcutaneous plane. Care is taken to ensure that the passing instrument does not penetrate the 

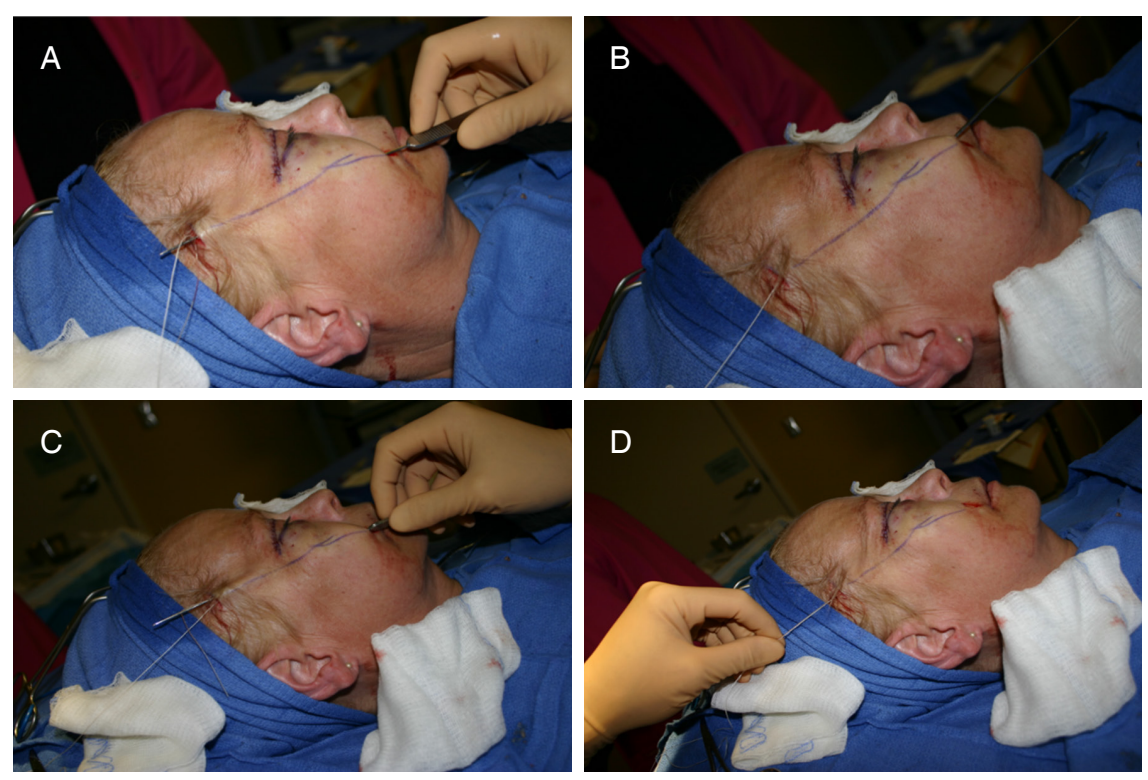

Figure 2. Technical details. A: The blunt passing instrument is introduced by stab incision up through the fixation incision. The Vicryl suture is passed through the eye of the passing instrument; B: The passing instrument is withdrawn, pulling the suture through the malar fat pad; $\mathrm{C}$ : The suture is engaged in the malar fat pad and then the tip of the passing instrument is passed up through the fixation incision; $\mathrm{D}$ : The suture is drawn out of the passing instrument. The passing instrument is removed through the naso-labial stab incision and the suture can then be secured to the temporal fascia

overlying skin or the underlying facial muscles. A 3-0 Vicryl, PDS absorbable suture, or 4-0 nylon clear permanent suture is threaded through the eye of the instrument and the suture needle is held in a needle diver. The instrument is then partially withdrawn through the stab incision [Figure $2 \mathrm{~A}$ and $\mathrm{B}$ ]. A mark on the instrument demarcates how close the tip of the instrument is to the puncture site so that the tip is not fully withdrawn. The passing instrument is re-advanced taking care to engage the malar fat pad tissue. The insertion path of the needle is in a slightly different path within the malar fat pad [Figure $2 \mathrm{C}$ and D]. The tip of the passing instrument exits the fixation incision and the suture is then withdrawn from the instrument leaving the two ends. The needle of the suture can then be used to attach the suture to the deep temporal fascia. Tension is placed on the suture to elevate the malar fat pad to the desired level. The suture is then secured to the deep temporal fascia. The temporal incision is closed using deep dermal sutures and subcutaneous sutures, and the stab incision is closed using 5-0 subcutaneous chromic suture.

\section{Patients}

An institutional review board-approved retrospective review was performed to identify all patients who underwent a MIMS procedure between 2008 and 2018. Preoperative and postoperative photographs were reviewed as was the electronic medical record. There were a total of 71 patients, 59 females and 12 males with an average age of 59 years.

\section{RESULTS}

A representative case is illustrated and described in Figure 3. There have been no major complications in any of the patients. No revision or re-elevation was necessary. Long-term results were assessed subjectively by patient report and surgeon examination. They were found to have been very satisfactory and lasting.

\section{DISCUSSION}

Various techniques have been described to correct malar fat pad ptosis, including open surgical approaches and closed procedures ${ }^{[1-3,8,10,11,13-17]}$. In terms of minimal access procedures, endoscopic techniques with 

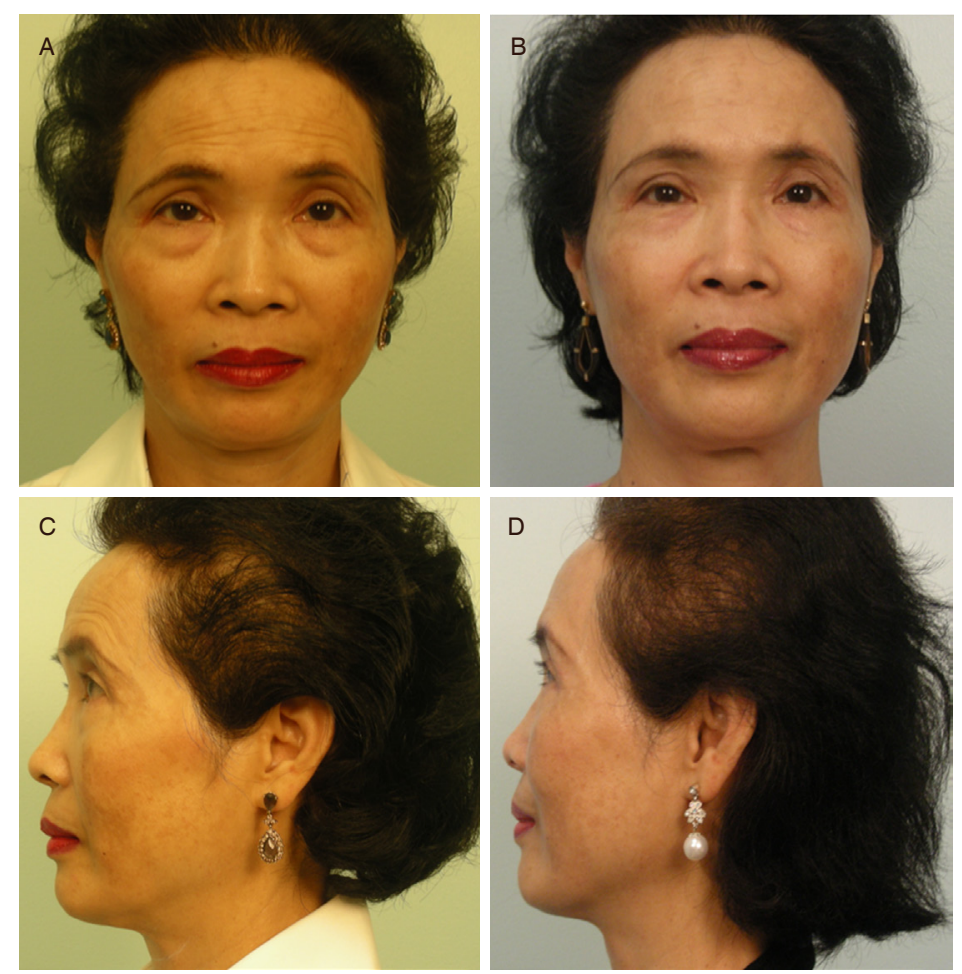

Figure 3. Long-term follow-up of a 57-year-old patient undergoing minimally invasive midface suspension procedure: A: preoperative frontal view; B: postoperative frontal view (eight months); C: preoperative lateral view; D: postoperative lateral view (eight months). The patient maintained satisfactory results at the 18-month follow-up visit.

extensive subperiosteal dissection have been described ${ }^{[13]}$. These approaches may involve longer operative times, general anesthesia, lengthy recovery periods, and a higher risk of complications. Additionally, numerous studies describing thread lifts have been published. Thread lifts generally involve inserting a unidirectional suture with cones or barbs subcutaneously ${ }^{[9,10,16,17]}$. The tissue is then manually inset over the barbs or cones. The advantages of this technique are short procedure time and very limited dissection. Disadvantages of thread lifts include minimal fat pad elevation, reaction and extrusion of sutures, and temporary results.

The technique in this study involves making a small temporal incision and a small stab incision near the nasolabial fold. The malar fat pad is elevated by suspending it to the deep temporal fascia using a standard suture. Unlike thread lifts, which only elevate the skin, the technique in this study directly elevates the malar fat pad. This distinction is important because the ideal way to address midfacial aging is by elevating the malar fat pad to its original and youthful position over the malar eminence. In our series, we initially used permanent nylon suture; however, with the success of the absorbable barbed suture, we initiated the use of absorbable sutures. The monofilament sutures left a palpable area along the suture and a knot, which the Vicryl suture avoided. Although the suture material dissolves within a few weeks, the results last longer. Although nylon suture is frequently used for midface elevation, absorbable sutures including catgut, Vicryl, and PDS have been used to elevate the face with success ${ }^{[18-21]}$. This may be because the malar fat pad is anchored to the fixed tissue of the deep temporal fascia, unlike thread lifts, which typically involve floating sutures. The difference in fixation may account for results which last longer than those from the modified sutures since the malar fat pad is suspended to the deep temporal fascia. Although a stab incision is made in a visible area of the face, in all patients, the scar was extremely well-tolerated and imperceptible.

Although this technique has several advantages and satisfactory results, it does have limitations. MIMS is not ideals for patients with severe skin laxity; these patients are better served by traditional facelifts. 

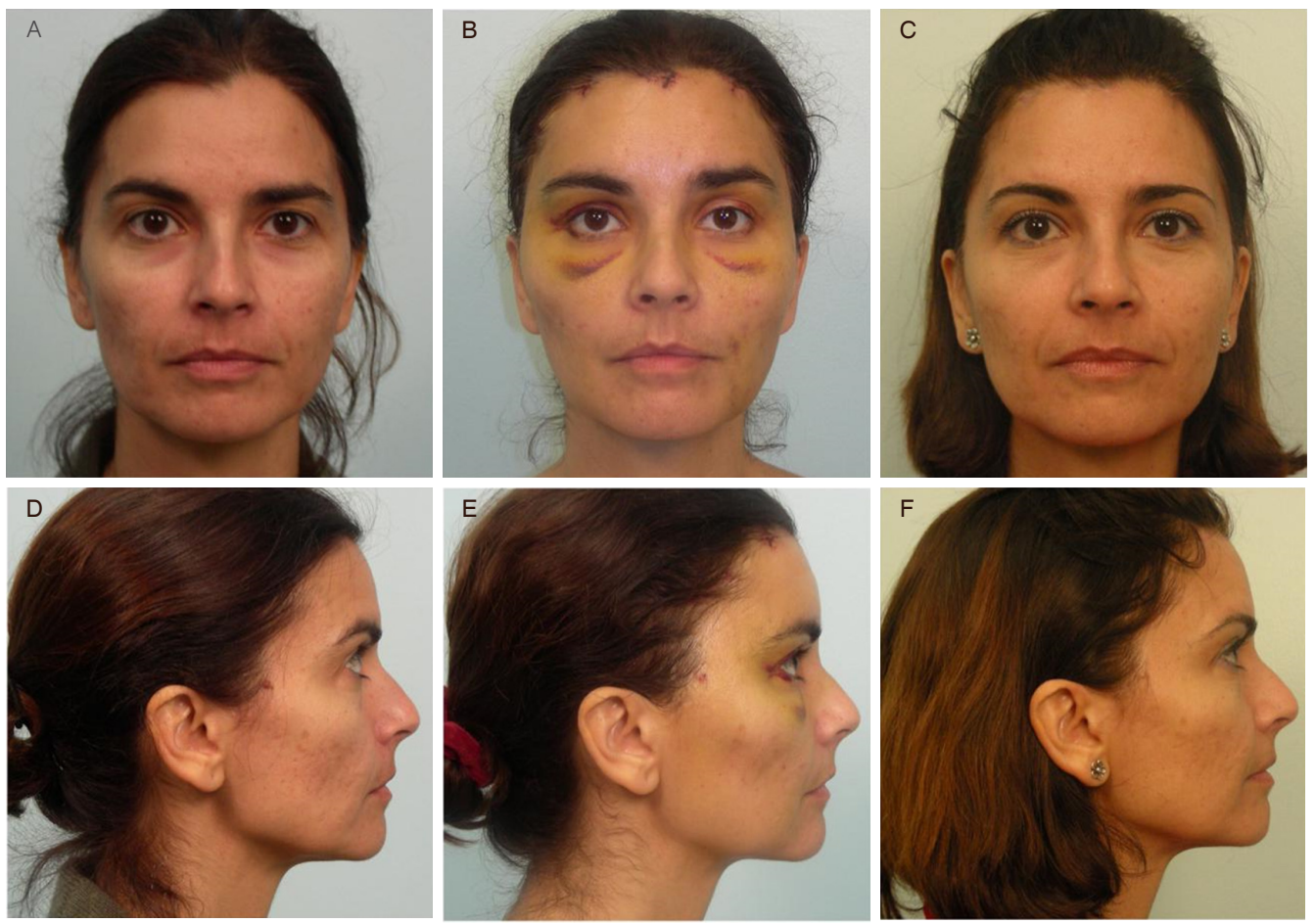

Figure 4. Short-term follow-up of a 47-year-old patient undergoing minimally invasive midface suspension procedure and resection of left temporal skin lesion: A: preoperative frontal view; B: immediate frontal view postoperative ( 6 days); C: postoperative frontal view ( 9 months); F: preoperative lateral view; E: immediate postoperative frontal view (6 days); and F: postoperative lateral view (9 months).

Therefore, the ideal candidates for minimally invasive midface suspension have mild-to-moderate skin laxity and are generally middle-aged seeking limited improvement. Periorbital pleating and wrinkling may occur if this procedure is performed in patients with significant skin laxity. However, in patients with some excess skin, a limited skin excision can be included. In addition, this procedure can be combined with another procedure, such as facial resurfacing, blepharoplasty, and fat grafting. Patients have self-reported satisfaction with outcomes that match or exceed those of other minimally invasive procedures; however, more studies are needed to better assess the longevity of the results.

\section{DECLARATIONS}

\section{Authors' contributions}

Review of data, supervision, editing: de la Torre JI

Writing, original draft: Lindsey Jr. J

Data curation: Cerio D

Conceptualization: Vasconez LO

\section{Availability of data and materials}

Data and material are maintained at UAB Plastic Surgery.

\section{Financial support and sponsorship}

There was no financial support. The project was supported by UAB Plastic Surgery.

\section{Conflicts of interest}

All authors declared that there are no conflicts of interest. 


\section{Ethical approval and consent to participate}

Institutional Review Board approval was obtained.

\section{Consent for publication}

The authors give consent for publication. Photographic consent was obtained for all patients.

\section{Copyright}

(c) The Author(s) 2020.

\section{REFERENCES}

1. de la Torre JI, Martin SA, Vásconez LO. Suture suspension of the malar fat pad. Aesthet Surg J 2002;22:446-50.

2. Engle RD, Pollei TR, Williams EF. Endoscopic midfacial rejuvenation. Facial Plast Surg Clin North Am 2015;23:201-8.

3. Tonnard P, Verpaele A, Monstrey S, Van Landuyt K, Blondeel P, et al. Minimal access cranial suspension lift: a modified S-lift. Plast Reconstr Surg 2002;109:2074-86.

4. Chaiet SR, Williams EF. Understanding midfacial rejuvenation in the 21st century. Facial Plast Surg 2013;29:40-5.

5. Gamboa GM, de La Torre, Jorge I, Vasconez LO. Surgical anatomy of the midface as applied to facial rejuvenation. Ann Plast Surg 2004;52:240-5.

6. Collawn SS, Vasconez LO, Gamboa M, Guzman-Stein G, Carriquiry C. Subcutaneous approach for elevation of the malar fat pad through a prehairline incision. Plast Reconstr Surg 1996;97:836-41.

7. de la Torre, JI, Rosenberg LZ, De Cordier BC, Gardner PM, Fix RJ, et al. Clinical analysis of malar fat pad re-elevation. Ann Plast Surg 2003;50:244-8.

8. De Cordier BC, de la Torre JI, Al-Hakeem MS, Rosenberg LZ, Costa-Ferreira A, et al. Rejuvenation of the midface by elevating the malar fat pad: review of technique, cases, and complications. Plast Reconstr Surg 2002;110:1526-36.

9. Ugurbas SH, Goldberg RA, McCann JD, Shorr N, Murthy R, et al. Suture midface suspension. Head Face Med 2006;2:35.

10. Ogilvie MP, Few JW, Tomur SS, Teven CM, Semersky AJ, et al. Rejuvenating the face: an analysis of 100 absorbable suture suspension patients. Aesthet Surg J 2018;38:654-63.

11. Lindsey JT. Five-year retrospective review of the extended SMAS: critical landmarks and technical refinements. Ann Plast Surg 2009;62:492-6.

12. Chopan M, Buchanan PJ, Mast BA. The minimal access cranial suspension lift. Clin Plast Surg 2019;46:547-57.

13. Saltz R, Ohana B. Thirteen years of experience with the endoscopic midface lift. Aesthet Surg J 2012;32:927-36.

14. Abraham RF, DeFatta RJ, Williams EF. Thread-lift for facial rejuvenation: Assessment of long-term results. Arch Facial Plast Surg 2009; $11: 178-83$.

15. Keller GS, Namazie A, Blackwell K, Rawnsley J, Khan S. Elevation of the malar fat pad with a percutaneous technique. Arch Facial Plast Surg 2002;4:20-5.

16. Laferriere KA, Castellano RD. Experience with percutaneous suspension of the malar fat pad for midface rejuvenation. Facial Plast Surg Clin North Am 2005;13:393-9.

17. Sasaki GH, Cohen AT. Meloplication of the malar fat pads by percutaneous cable-suture technique for midface rejuvenation: outcome study (392 cases, 6 years' experience). Plast Reconstr Surg 2002;110:635-54.

18. Owsley JQ, Zweifler M. Midface lift of the malar fat pad: technical advances. Plast Reconstr Surg 2002;110:674-85.

19. Fitzgerald R, Graivier MH, Kane M, Lorenc ZP, Vleggaar D, et al. Update on facial aging. Aesthet Surg J 2010;30 Suppl:11S-24S.

20. McCollough EG, Scurry WC, Shirazi MA. The "Midface-Lift" as a misnomer for correctly identifying procedures designed to lift and rejuvenate the cheeks and malar regions of the face. Arch Facial Plast Surg 2009;11:257-62.

21. Owsley JQ Jr, Zweifler M. Midface lift of the malar fat pad: technical advances. Plast Reconst Surg 2002;110:674-85. 